\title{
Are Printed Transit Information Materials a Significant Barrier to Transit Use?
}

\author{
Alasdair Cain, Center for Urban Transportation Research
}

\begin{abstract}
This study investigated the extent to which the lack of ability to use printed transit information materials correctly to plan transit trips is a barrier to transit use. A total of 180 people were asked to undertake two transit trip-planning assignments, each requiring the use of a system map, two route maps, and two schedules.

The study found that only 52.5 percent of the sample, composed of both transit users and nonusers, was able to plan a transit trip successfully using standard printed information materials. The main problems existed at the latter stages of the tripplanning process involving schedule use ( $55.6 \%$ success rate). Although printed information materials were the most popular trip-planning media for transit users, more than half stated that they did not use this method to plan their trips.

Additional questioning suggested that a relationship between transit trip-planning ability and transit use does exist. However, it was also found that while lack of information material comprehension is a problem, it is not a primary barrier to transit use-none of the nontransit users cited lack of transit trip-planning ability as their main reason for not using transit. Furthermore, a wide range of other information resources is available for transit users to choose from if they are uncomfortable with printed media.
\end{abstract}




\section{Introduction}

Printed information materials, such as transit system maps, route maps, and schedules, are the traditional media used by transit agencies to provide service information to customers. Transit providers allocate significant resources in producing such materials and in keeping them up to date with service modifications. There is some concern in the transit industry that public inability to plan transit trips may be a major barrier to transit use. However, relatively little is known about how transit users actually plan their trips, and the extent to which printed information materials are actually used.

This article presents the results of a study completed by the National Center for Transit Research, titled "Design Elements of Effective Transit Information Materials" (Cain 2005). The first objective of the study was to isolate the different design elements that make up printed transit information materials, to determine which design options maximize public trip-planning ability. For more information in relation to this objective, see Cain (2005). The focus of this article is the study's second objective, which was to determine the extent to which transit information materials are a barrier to transit use, by exploring the relationship between transit trip-planning ability and transit usage.

\section{Literature Review}

The Transit Cooperative Research Program (TCRP) Report 95 is a series of individual studies assessing how different types of transportation system changes and policy actions affect traveler responses and aggregate travel demand. Chapter 11 assessed how various types of transit information and promotion activities impact ridership. The study stated that the primary goal of transit information and promotion activities is to increase ridership or net revenues, preferably both (Turnbull 2003). Other secondary objectives included retaining existing riders, increasing the frequency of use among current riders, getting nonriders to try the system, and increasing general public awareness of available service options. An understanding of the importance of information and promotion, and the difference between these two terms, is key to this discussion. As noted by Turnbull (2003),

For a person to make use of transit service, and thus become a transit rider, he or she must know of the service and understand how to use it. Moreover, the understanding of how to use the service must be complete enough to overcome the barrier to use posed by unfamiliarity. Transit information activities may thus attract 
potential riders to both transit in general and to particular services by informing them about the options available and how to make use of them. Transit promotion seeks to provide that extra nudge for potential riders to make the leap and actually try riding transit, and hopefully become regular users.

Only 55 percent of the U.S public claims to be familiar with transit (Wirthlin Worldwide and FJCandN 2000).

The TCRP-95 report (Turnbull 2003) referenced the large variety of information sources available, including bus stop signage, telephone information (via call centers-either automated or staffed), Internet resources such as on-line transit trip planners, and oral instruction from transit staff or fellow passengers, as well as printed information materials. The report divided the different information and promotion options into six categories: (1) mass market information, (2) mass market promotions, (3) targeted information, (4) targeted promotions, (5) ongoing customer information services, and (6) real-time transit information (Turnbull 2003). Printed transit information materials appeared in two categories: mass market information, which included brochures, system maps, bus stop signage, telephone information systems, and websites; and targeted information, which included route- or sector-specific maps and schedules.

The report noted that relatively few published examinations of the impacts of transit information and promotion activities on ridership are available. This was attributed to a more general problem associated with evaluating marketing impacts on ridership, caused by many agencies lacking a ridership tracking database. In many cases, rider surveys are used to provide impact assessment data, but the accuracy of these can be questionable as they track stated or intended behavior, not actual behavior, and may also suffer from self-selection bias (Turnbull 2003).

Published research on the impact of mass market information programs, such as door drops of printed transit information material, showed that while such campaigns have proven effective in raising awareness and use of transit service support systems, they have little impact on attracting new riders. Results in relation to increased frequency of use by existing riders have also been mixed. Adding incentives to mass market information programs increases the likelihood of ridership gains, at least in the short term-published results show ridership gains of between 4 and 35 percent (Turnbull 2003). Long-term ridership gains are much more difficult to achieve. 
Targeted information programs have been shown to be much more effective than mass market information in generating ridership gains. These can include geographical targeting, such as the campaign conducted by the Niagara Frontier Transportation Authority in Buffalo, New York, that mailed route information materials to more than 20,000 resident living within three quarters of a mile of six bus routes. Targeted information also includes socioeconomic targeting (Turnbull 2003). This was featured in the above campaign, with the targeted areas selected on the basis of population profiles being congruent with those of transit riders. Farebox revenue analysis showed that revenues on these targeted routes had increased 1 to 3 percent on three routes and 11 to 33 percent on the other three routes (TTI 1999). Increases of more than 50 percent have been reported in the short term in relation to other targeted information programs.

Transit information usefulness will also be affected by each potential user's knowledge of local geography, knowledge of the transit system, and ability to process different types of information, including maps and schedules. A study conducted in 1986 found that 64 percent of the U.S. population is thought to have difficulty reading maps of any sort (Streeter and Vitello 1986). Data from the National Adult Literacy Survey found that many people are unable to use a tabular bus schedule successfully. This survey tests adult literacy levels in three separate categories: prose comprehension, document literacy, and quantitative literacy. In the document literacy section, only 37.6 of adults between 21 and 25 years old were able to use a bus schedule successfully to select the correct bus departure time (Kirsch et al. 2001). As such, using a bus schedule was rated at level 4 on a five-point scale, with level 1 being the easiest and level 5 the most difficult.

Despite these difficulties, printed information materials remain the dominant transit trip-planning media. A study titled "Customer Preferences for Transit ATIS" found that "riders prefer traditional forms of paper-based information and traditional wayside signage (e.g., schedules, maps, and fares)" (Cluett et al. 2003), while TCRP Report 45 (Higgins and Koppa 1999) stated that both transit riders and nonriders often mention timetables (schedules) as a potentially useful information aid, which some riders use regularly. The report further stated that many people find timetables difficult to read and understand and recommended that "rather than print and distribute timetables, systems provide departure times or bus headways on bus stops signs, packaging the schedule information into smaller, manageable pieces" (Higgins and Koppa 1999). However, the headway-based approach is limited to situations where service is frequent enough that transit users do not need 
to know exactly when their bus will arrive. Research suggests that this "schedule use threshold" lies at around 10 to 15 minutes, with the majority of users being "random arrivals" at bus stops if headways are 10 minutes or less, while at headways of 15 minutes or more, the majority of users are "planned arrivals" requiring schedules (Balcombe and Vance 1998). One study provided anecdotal evidence that appreciable gains in ridership have been made when schedules have been reorganized to a simpler "clockface" format (Webster and Bly 1980). Thus, the level of service complexity is also a factor, with complicated route structures and unstandardized departure times adding to the likelihood of rider confusion and affecting which information provision styles can be used. Considering the fact that transit users are often from low-income, low-education backgrounds, the extent of the challenge in providing understandable trip-planning materials is clear.

\section{Study Objective}

The literature review indicated that transit information is crucial to the overall success of a transit service. Although a wide variety of different information media are available, traditional printed information materials remain very popular. However, the review also showed that many transit users, and the public in general, are unable to plan their trips successfully using such materials. Therefore, this study was designed to investigate in more detail the extent to which the general public can successfully use printed information materials to plan a transit trip, and to isolate the aspects of the trip-planning task that cause difficulty. The study then assessed the extent to which transit trip-planning problems affect actual transit usage to determine whether transit information materials are a significant barrier to transit use.

\section{Study Design}

A total of 180 people were recruited at three shopping mall sites in the Tampa Bay area in August 2004. Quotas were used to ensure sample variation on age, gender, ethnicity, income level, and transit use (35.6\% of the sample used transit at least once a week on average). As the study did not obtain a random sample, the "raw" results could not be used to draw population-wide inferences. To address this, three different weighting factors (a demographic adjustment factor, a travel behavior adjustment factor, and a systematic adjustment factor) were applied to the data to correct for any sample bias. For more detailed information on the 
study methodology and data weighting process, see the final project report (Cain 2005).

Each participant was asked to undertake two transit trip-planning assignments. Each assignment involved planning a bus trip that required the use of two bus routes to travel from a specified origin to a specified destination, arriving before a specified time. Thus, each assignment involved one transfer, and required the use of a transit system map, two route maps, and two schedules. Research staff timed and observed participants as they undertook the trip-planning assignments and interviewed them after each assignment. Following the assignments, participants were asked how confident they would be if they had to plan a transit trip using similar materials in "real-life" and whether their participation would have any impact on their future transit usage. Current transit users were also asked to describe the main method they used to plan their transit trips, while nonusers were asked to state the main reason why they did not use transit. A total of 358 test observations resulted from the study.

\section{Assessment of Aggregate Transit Trip-Planning Ability}

The trip-planning process was divided into five discrete stages, as shown in Table 1. Stage 1 involved using the system map to identify the trip origin and trip destination. This was a straightforward task for most participants, and the two points were located either by using the street addresses provided, or simply scanning the system map at random until the points were found. Stage 2 involved using the system map to determine which bus routes to use for their trip. This required locating different color-coded routes in close proximity to their trip origin and destination, following the routes through the town, and deciding where to transfer. This was again a simple task for most participants, and Table 1 shows a success rate of 93.6 percent on these first two stages.

Having identified the routes required for their trip, participants were provided with the route maps and schedules for each of these routes, and asked to use them to identify the bus stops and times for boarding and disembarking each bus (if they had not been able to identify the required routes correctly, this was explained to them before they were given the correct route maps and schedules).

The first part of this process (Stage 3) was to identify the four time points (bus stops) required for the trip (first route start point, first route end point, second route start point, and second route end point). In most cases, the points of interest 
Table 1. Sample Performance at Each Transit Trip-Planning Stage

\begin{tabular}{lllc}
\hline Stage & Description & $\begin{array}{l}\text { Information } \\
\text { Materials Used }\end{array}$ & $\begin{array}{l}\text { Success } \\
\text { Rate (\%) }\end{array}$ \\
\hline 1 & $\begin{array}{l}\text { Locating origin and } \\
\text { destination on system map }\end{array}$ & System map & 93.6 \\
2 & $\begin{array}{l}\text { Selecting bus routes } \\
\text { and transfer point }\end{array}$ & System map & 73.2 \\
\hline 3 & $\begin{array}{l}\text { Locating closest time } \\
\text { points/transfer time point }\end{array}$ & System map/route map & \\
\hline 4 & $\begin{array}{l}\text { Identifying correct } \\
\text { section of schedule }\end{array}$ & Route map/schedule & 55.6 \\
5 & $\begin{array}{l}\text { Using schedule } \\
\text { to get bus times }\end{array}$ & Schedule & 52.5 \\
\hline
\end{tabular}

(which included the specified origin and destination points) were not provided on the route maps, so participants had to cross-reference between the system map and the route maps to locate the closest bus stops and the appropriate transfer point. Table 1 shows a relatively high level of success at this stage, with 73.2 percent of assignments successfully completed.

Having identified the boarding and alighting bus stops, participants were then required to begin the task of identifying the times at which they would board and disembark from each bus. The first stage in this process (Stage 4) was to determine which section of the schedule to use. This requires an awareness of (1) the required direction of travel, (2) the required day of travel, and (3) whether the trip is in the morning or afternoon. Each issue affected the determination of which part of the schedule to use, and all three issues were a source of difficulty for study participants. Additional information on these issues can be found in Cain (2005).

The final stage in the trip-planning process (Stage 5) was to use the schedule to identify the correct bus times for boarding and disembarking from each bus (first route boarding time, first route alighting time, second route boarding time, and second route alighting time). Table 1 shows that Stages 4 and 5 caused the most problems for participants, with a success rate of only 55.6 percent. Just under half the sample got at least one bus time wrong, while almost one fifth of the sample 
(17.9\%) was unable to get any of the times correct. Following the exercise, participants were asked which parts of the assignments were the most difficult. Using the schedule was identified as the most difficult aspect on 162 occasions (almost half of all completed assignments), adding further evidence to the conclusion that schedule use is by far the most difficult aspect of the transit trip-planning task.

Overall, only 52.5 percent of assignments were successfully completed, suggesting that a significant proportion of the general public is unable to successfully plan a bus transit trip from an origin to a destination that involves one transfer. However, in dividing the trip-planning task into a series of five discrete stages, this study suggests that most people are able to complete the first three trip-planning stages successfully, and that the critical problem lies at Stages 4 and 5, where they are required to use a schedule to determine boarding and alighting times. This is consistent with the findings of other research, as discussed in this article's literature review. Therefore, the main conclusion from this part of the study was that there is a critical need to improve the public's ability to understand and utilize the information presented in transit schedules. Having found that a significant portion of the public has difficulty planning a transit trip, the next question to consider was the extent to which this affects public confidence in using transit, and, in aggregate terms, how this affects transit ridership. This topic is addressed in the remainder of this article.

\section{Characteristics of Current Transit Information Material Use}

Study participants were asked to indicate, in the post-test self-completion questionnaire, whether they had ever used transit schedules or maps before participating in the study. Their responses are provided in Table 2, stratified by their stated current frequency of transit use.

Table 2 shows that the level of previous experience with transit schedules and maps is different for transit users and nonusers. The majority of transit users (73.2\%) had previous experience with transit information materials, while only around half of nontransit users (49.3\%) had previous experience. Interestingly, more than one quarter of the sampled transit users (26.8\%) did not have previous experience, suggesting that a significant number of transit users do not use maps and schedules to plan their transit trips. This issue was investigated further by asking transit users in the sample to state the main method they used to plan their transit trips. Their responses are provided in Figure 1. 


\section{Table 2. Level of Previous Experience with Transit Information Materials by Transit User Status}

\begin{tabular}{lcccc}
\hline $\begin{array}{l}\text { Whether Participant Has Previous Experience } \\
\text { with Transit Information Materials }\end{array}$ & \multicolumn{2}{c}{ Transit Users } & \multicolumn{2}{c}{ Nontransit Users } \\
No previous experience & 30 & 26.8 & 34 & 50.7 \\
Previous experience & 82 & 73.2 & 33 & 49.3 \\
\hline Total & 112 & 100 & 67 & 100 \\
\hline
\end{tabular}

Figure 1. Main Method Used by Transit Users to Plan Transit Trips

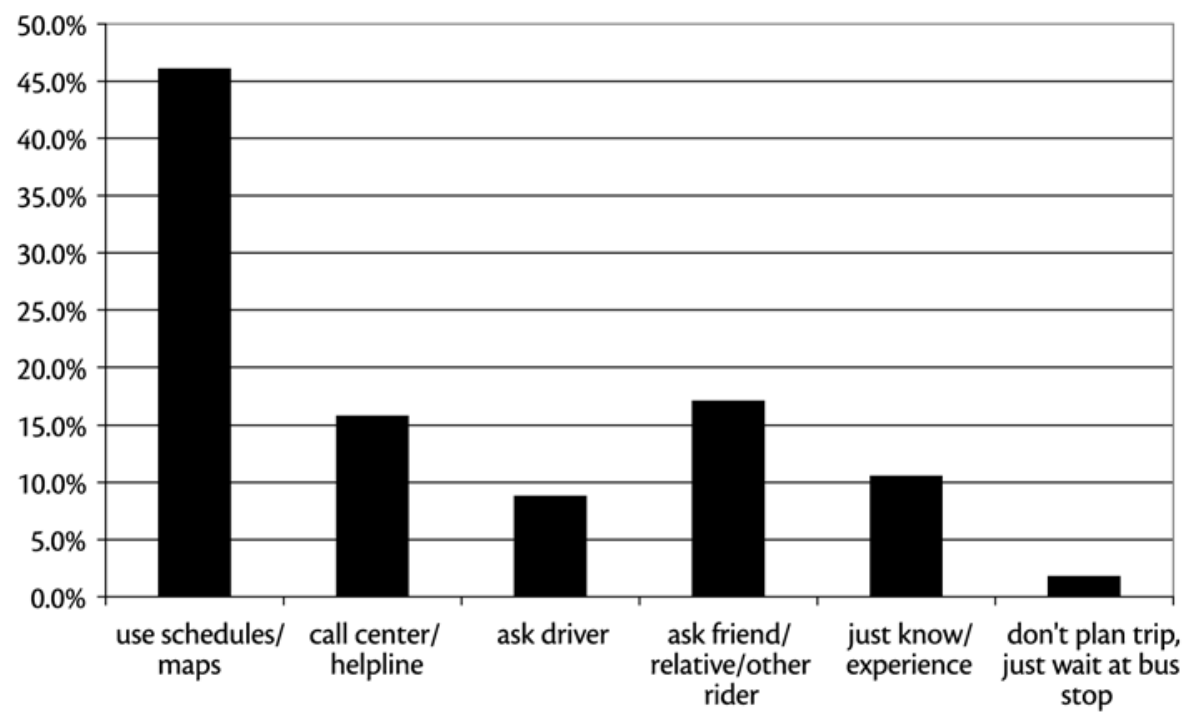

Figure 1 shows that just under half of transit users in this sample used transit schedules and maps to plan their transit trips. Although this was by far the most popular method overall, more than half of the transit users used a different approach. Alternatives included calling a helpline (16\%) or asking the bus operator (9\%), both of which require transit agency resources. Thus, improving transit user ability to plan their own trips may allow drivers to complete their routes in less 
time, and would mean that less staff resources would be spent answering requests for assistance from customers.

Just over 10 percent of transit users stated that they did not need any method to plan their trip as they simply knew from experience where and when the transit services ran. A small proportion of the sample did not employ any trip planning, and simply stood at the bus stop until a bus came. Further analysis was conducted to assess whether there was any variation in trip-planning method used in relation to different frequencies of transit use. Table 3 provides the results of this analysis. Although the cross-tabulated cell sizes are relatively small, the majority of those who use schedules and maps to plan their transit trips are frequent transit users, with 38.5 percent using the bus four or more times a week and 28.8 percent using the bus one to three days a week. Similar results were observed for people who call a helpline, with again more than half using the bus at least once a week. Frequencies are more evenly spread for people who ask the driver or ask a friend/relative, while almost all those who stated they knew the transit services from experience were also frequent transit users.

\section{Impact of Study Participation on Transit Trip-Planning Confidence}

At the end of the exercise, participants were asked whether participation in the exercise had increased their confidence in planning a transit trip. Results are shown in Table 4, stratified by level of previous experience with transit information materials.

Table 4 shows that around two thirds of study participants stated that participation had improved their trip-planning confidence. Furthermore, it appears that whether the participant had previous experience with such materials did not have an effect on this-almost as many participants with previous experience stated a positive impact (66.1\%) as those who had never used such materials before (70.3\%). This suggests that even people who already use such materials could benefit from further training or instruction. Around one quarter of the participants from each group stated that participation had not increased their confidence.

Further analysis assessed how participants' performance during the exercise varied by their stated level of confidence in transit trip planning following exercise completion. Results of this analysis are shown in Table 5. Inferential statistics were 


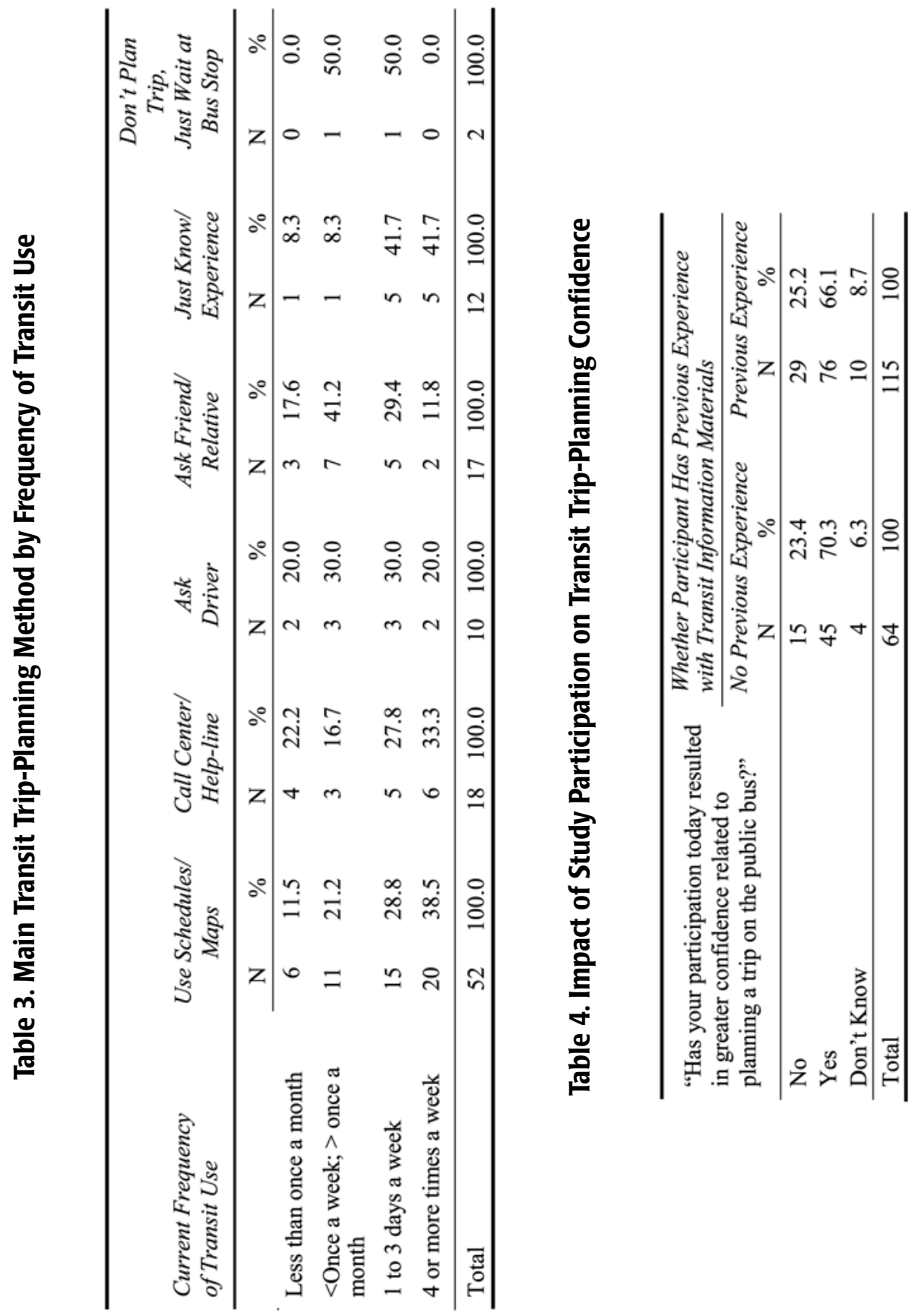


used to assess the strength of the relationship between these two variables. Eta is a correlation coefficient that measures the strength of bivariate relationships. An Eta score of 0 means there is no relationship, and the higher the Eta value is, toward a maximum of 1 , the greater the strength of the relationship in the sample data. The statistical significance value (Sig.) is used to assess the probability that the relationship observed in the sample, as described by the Eta value, would also exist in the population from which the sample was drawn. A significance value of 0.05 indicates a 95 percent probability that the relationship observed in the sample will also exist in the population.

The statistics computed in Table 5 show that no significant differences exist in the performance of those who were more confident following the survey, and those who were less confident. Indeed, in most cases, the scores of all three groups are very similar, suggesting that actual assignment performance is not related to how confident participants felt after the assignments were completed. Participants who had made mistakes thought they had completed the assignments successfully, stating that they found the assignments "easy" or "very easy." Overall, this table suggests that many people are unaware of their trip-planning errors, and incorrectly believe that they are successfully planning their trips. This could be a source of customer frustration and complaints against transit services, as such customers would be prone to believing that their services are running late or have been cancelled, when in fact they have actually misread the schedule.

\section{Impact of Study Participation on Stated Future Transit Use}

Participants were next asked whether their use of public transit would change in any way following their participation in the study. Table 6 compares participant's current transit use frequency with their stated future transit use frequency. The information is presented in a matrix format with current frequency in the table rows and future frequency in the table columns. Numbers shown in bold indicate the number of participants who would not change their frequency of transit use.

Summing the numbers in bold indicates that a total of 140 people (77.8\%) stated that they would not change their frequency of transit use. Of the remaining 22.2 percent who indicated that their frequency of transit use would change; 8 people (4.4\%) stated that they would use transit with less frequency following the survey exercise. 


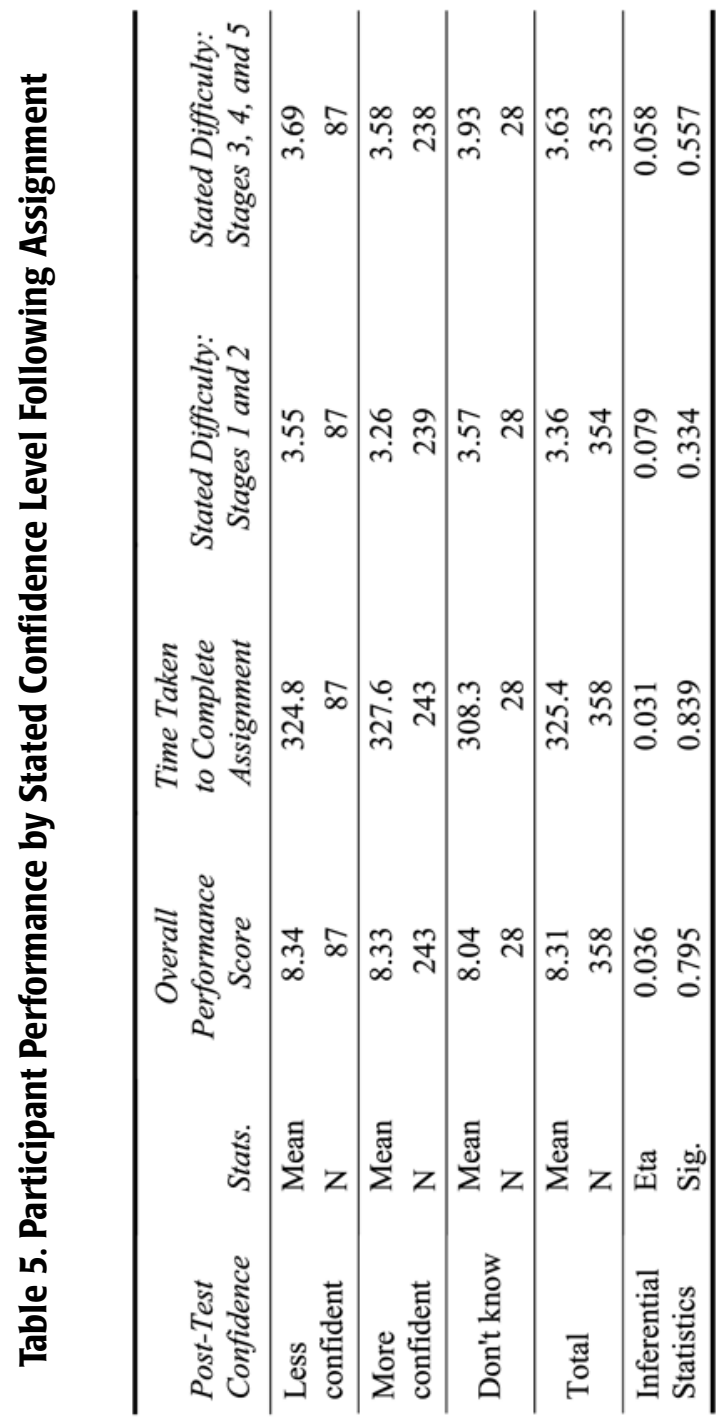




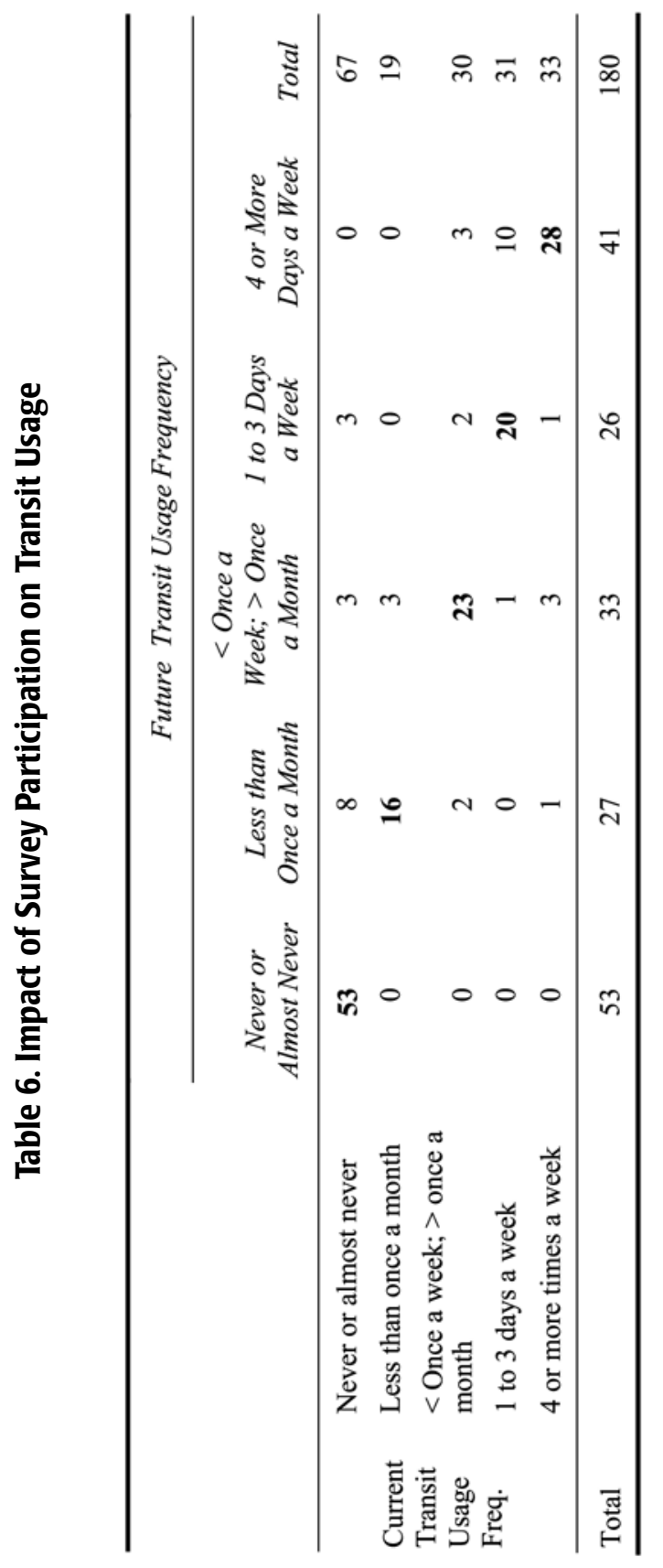


The remaining 17.8 percent ( 32 people) stated that their frequency of transit use would increase. Of the 67 participants who currently never or almost never use transit, 14 stated that they would use transit in future, meaning that 20.9 percent of nontransit users stated they would now use transit having gained experience in using transit information materials. Eight of these stated that they would now use transit less than once a month; 3 stated they would use it between once a month and once a week; and 3 stated they would now use transit one to three days a week. Some participants who currently use transit also stated that they would increase their future use: of the 31 people who currently use transit one to three days a week, 10 stated that they would now use transit four or more times a week. While these results could be viewed as evidence of a relationship between study participation and increased future transit use, it must be noted that stated behavior change does not equate to actual behavior change, and also that the sample size used here is too small to be considered statistically robust.

A further investigation was carried out to determine whether any link existed between participants' performance on the different stages of the assignment and their stated future frequency of transit use. Table 7 compares the performance of three groups: those who stated they would use transit with less frequency than before; those who would not change their transit use; and those who stated they would use transit with greater frequency.

Table 7 shows no significant differences in the performance of the three groups in terms of overall score and total time taken on the assignments. However, significant differences were observed in terms of stated difficulty, for both Stages 1 and 2 and Stages 3, 4, and 5. In each case, the highest stated difficulties were observed among those stating that they would now use transit less, and the lowest stated difficulty among those stating that they would now use transit more. The mean score for people who would now use transit more equated to a difficulty rating of "somewhat easy," while the mean scores for the other two groups equated to a difficulty rating of "neither difficult nor easy." Clearly, participants who found the assignments easier, irrespective of their actual performance, were more likely to state that they would use transit more in future. This suggests a relationship between the perceived difficulty of the transit trip-planning task and the propensity to use transit. 


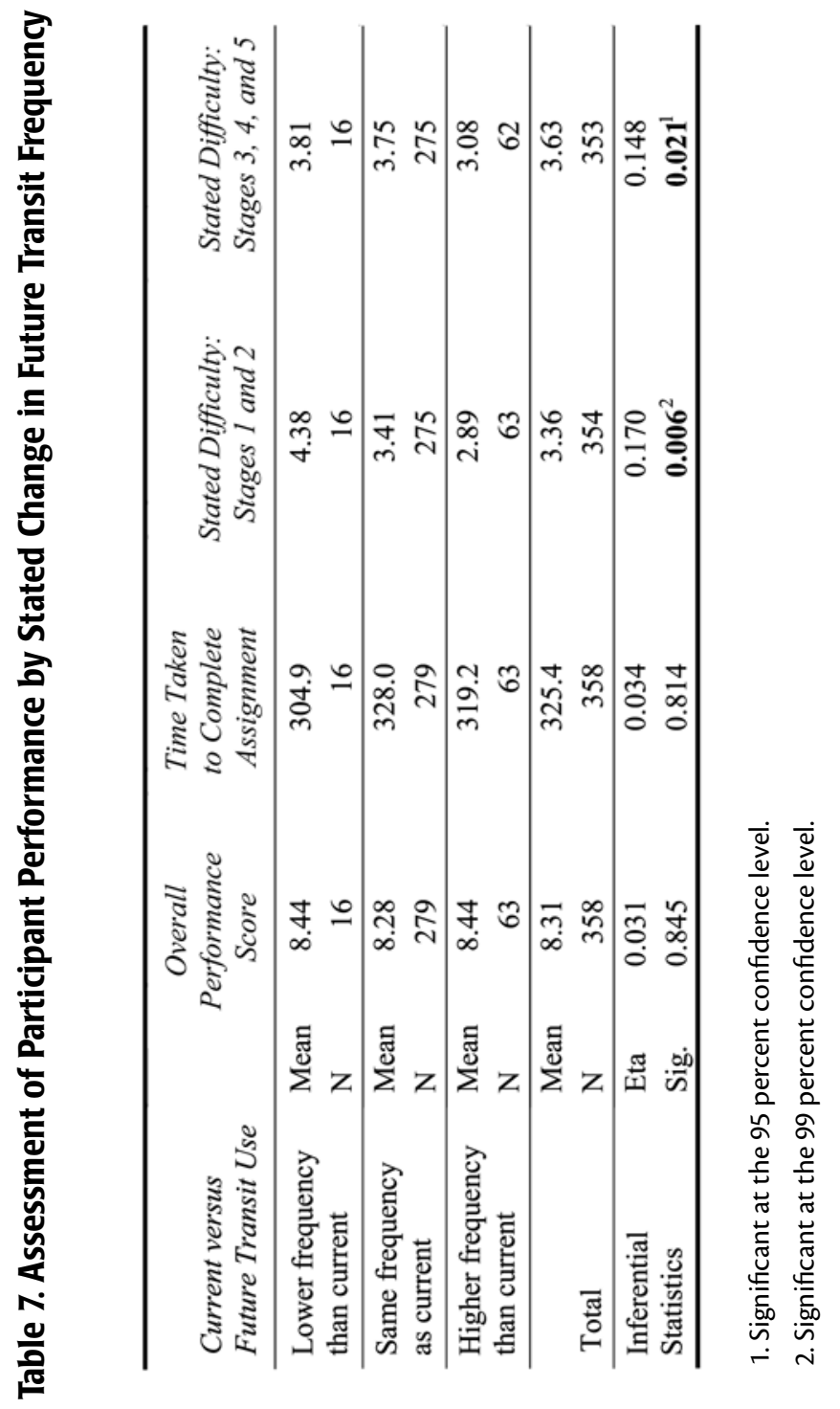




\section{Are Information Materials a Barrier to Transit Use?}

Results from the previous sections have suggested that many transit users do not use printed transit information materials to plan their transit trips. Furthermore, while the majority of the sample stated that participation in the exercise had increased their confidence in planning a transit trip, less than one fifth thought that they would now use transit services more often. This suggests that the lack of transit trip-planning ability using transit information materials is not a primary barrier to transit use. To clarify this, nontransit users were asked to state the main reason why they did not use transit. Their responses are provided in Figure 2.

Figure 2. Main Reason Why Nontransit Users Do Not Use Transit

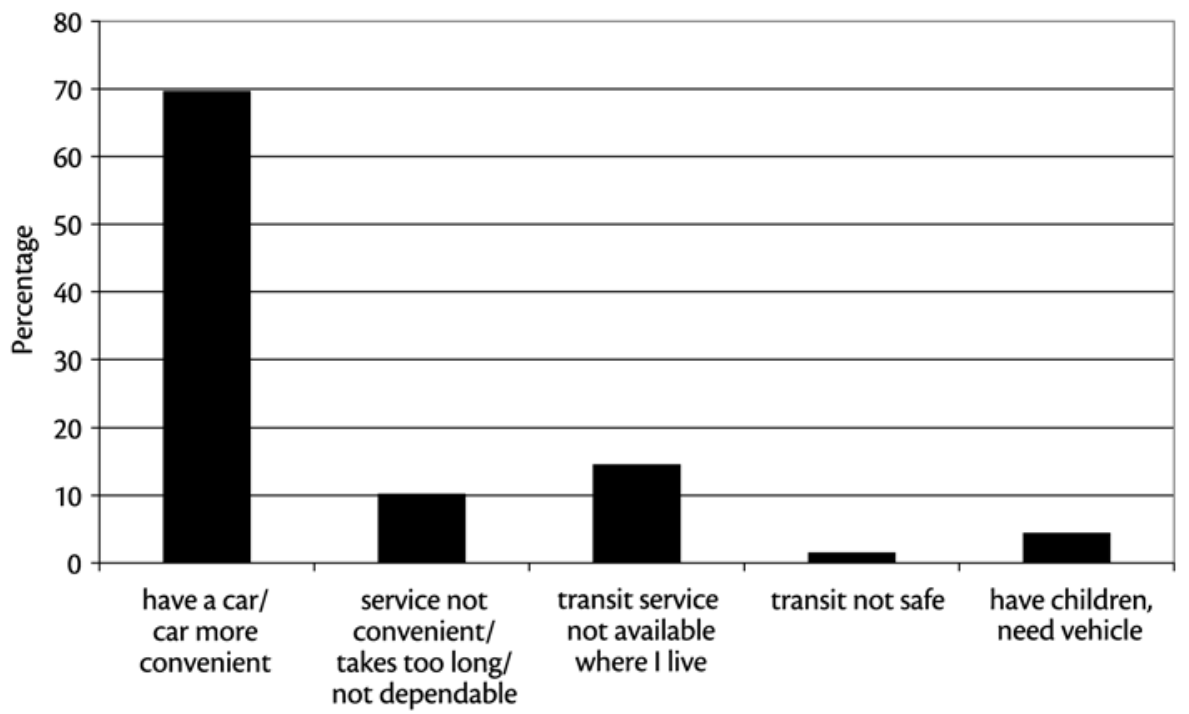

Figure 2 shows that the primary reason for nontransit use among nonusers is that they have access to a private vehicle ( $70 \%$ of nonusers). Other reasons given were that transit services are not convenient, dependable, or quick enough (10\%), or that there simply is not a service available for use (15\%). In discussions with interviewers following the survey exercise, several transit users stated that while weekday services were adequate, often no service is available on Sundays and public holidays. Complete lack of service is clearly a major barrier to transit use. In reference to this particular investigation, none of the participants cited transit 
trip-planning problems as their reason for not using transit. This suggests that lack of transit trip-planning ability is not a significant barrier to transit use.

\section{Conclusions}

This study has found that just over half $(52.5 \%)$ of a sample of transit users and nonusers in the Tampa Bay area was able to plan a transit trip successfully using printed information materials. The main problems existed at the latter stages of the trip-planning process, which involved the use of tabular schedules ( $55.6 \%$ success rate).

Approximately two thirds of the participants stated that their participation had increased their level of confidence in using printed transit information materials; 17.8 percent stated that their frequency of transit use would also increase. Furthermore, 20.9 percent of nontransit users stated that they would now use transit in future. However, these are only statements of future behavior, and should not be used to assume equivalent ridership gains. People who found the assignments easier, irrespective of their actual performance, were more likely to state that they would use transit more in future. This suggests a relationship between the perceived difficulty of the transit trip-planning task and the propensity to use transit.

Overall, this study has shown that a significant portion of the population has difficulty using traditional printed transit information materials, particularly schedules, to plan transit trips, irrespective of whether they use transit. This finding is corroborated by the results of other similar studies [see Streeter and Vitello (1986) and Kirsch et al. (2001)]. Given this fact, the next question to ask is whether these difficulties have an effect on transit usage. The findings of this study suggest that this is unlikely to be a significant problem. None of the nontransit users participating in the study cited lack of transit trip-planning ability as their main reason for not using transit. Also, although printed transit information materials were the most popular method of trip planning for transit users, a wide range of other resources are available, and more than half of the transit users in the study stated that they used these other methods to plan their trips.

Despite difficulties the public has in using schedules, it is still a very popular method for obtaining transit service information. Assuming that this will continue to be the case, serious attention must be given to ways to improve schedule design such that it will be understandable to a higher proportion of the population. 
Realistically, there will probably never be a design that every transit user can fully understand, but perhaps some progress can be made to raising the overall proportion. A few options for approaching this include:

- Continue to use the traditional tabular schedule as the design template, but investigate ways of improving its design to raise the overall level of comprehension.

- Investigate the use of alternatives to the tabular schedule, such as the "clockface" template, or the headway-based approach. However, such designs tend to reduce the completeness of the information that can be presented, and the trade-off between completeness and comprehension would have to be assessed.

- Provide a simplified text-based summary of the schedule information beside the full schedule for people who cannot read the schedule or do not require such accurate information.

- Results from this study showed that exposing the public to trip-planning exercises increased their level of confidence in planning an actual transit trip. Perhaps providing instruction or training in the correct use of the materials would be an effective way to improve trip-planning confidence and overall comprehension.

Another phase of the study is now being undertaken with the objective of investigating further the schedule comprehension issues outlined above. This study aims to develop a design guidelines document that can assist transit agencies in production of their printed information materials. This document will be available in fall 2007.

\section{References}

Balcombe, R. J., and C. E. Vance. 1998. Information for bus passengers: A study of needs and priorities. Transportation Research Laboratory-Report 330. Funded by the Department of the Environment, Transport, and the Regions, United Kingdom.

Cain, A. 2005. Design elements of effective transit information materials. National Center for Transit Research, Report 527-12. Center for Urban Transportation Research, University of South Florida. http://www.nctr.usf.edu/pdf/52712.pdf. 
Cluett, C., S. Bregman, and J. Richman. 2003. Customer preferences for transit ATIS: Research Report. Washington, DC: Federal Transit Administration, U.S. Department of Transportation.

Higgins, L., and R. Koppa. 1999. Passenger information services: A guidebook for transit systems. TCRP Report 45. Washington DC: Transportation Research Board, National Research Council, National Academy Press.

Kirsch, I. et al. 2001. Technical report and data file users manual for the 1992 national adult literature survey. National Center for Education Statistics, U.S. Department of Education, NCES 2001-457.

Streeter, L., and D. Vitello. 1986. A profile of drivers' map reading abilities. Human Factors 28 (2): 223-239.

TTI. 1999. Texas Transportation Institute, South West Transit Association, and the University of Wisconsin-Milwaukee. A handbook of proven marketing strategies for public transit. TCRP Report 50. Washington, DC: TRB, National Research Council.

Turnbull, K. F. 2003. Transit information and promotion. Chapter 11. Traveler Response to Transportation System Changes. TCRP Report 95. Washington, DC: TRB, National Research Council.

Webster, F. V., and P. H. Bly. 1980. The demand for public transport. Crowthorne, Berkshire, England: Transportation Research Laboratory.

Wirthlin Worldwide and FJCandN. 2000. Enhancing the visibility and image of transit in the United States and Canada. TCRP Report 63. Washington, DC: TRB, National Research Council.

\section{About the Author}

AlasdaIR CAIn (cain@cutr.usf.edu) is a Senior Research Associate at the Center for Urban Transportation Research (CUTR), University of South Florida. He is involved primarily in the research and evaluation of Bus Rapid Transit (BRT) systems and transit user information needs and the design of printed transit information materials. A native of Scotland, Mr. Cain holds a bachelor's degree in civil engineering from the University of Glasgow and a master's degree in transportation engineering from the University of South Florida. 